\title{
A cross-sectional audit of the risk of burnout among senior medical staff in a UK district general hospital
}

\author{
Authors: Anna Baverstock, ${ }^{\mathrm{A}}$ James Coulston $^{\mathrm{B}}$ and Mark Dayer $^{\mathrm{C}}$
}

\section{Objective}

The objective was to assess burnout in senior hospital doctors (consultants and staff grade, associate specialist and specialty (SAS) doctors) within a UK-based NHS district general hospital (DGH).

\section{Method}

A web-based survey was created using the validated abbreviated Maslach Burnout Inventory (aMBI) with consultants and SAS doctors in a DGH.

Primary and secondary outcome measures

We measured scores on aMBI subscales: depersonalisation, emotional exhaustion, personal accomplishment and efficacy.

Results

One-hundred and seventy-eight senior clinicians $(60 \%$ of consultant and SAS doctors) completed the survey with $85 \%$ of these being substantive consultants. Forty-nine per cent of senior clinicians were found to be at high risk of burnout using metrics from the aMBI.

Conclusions

Burnout is prevalent among senior clinicians at this DGH.

KEYWORDS: Burnout, consultant, staff and associate specialist

DOI: 10.7861/clinmed.2019-0161

\section{Introduction}

Burnout has been the topic of much interest and focus in the last few years within the medical and wider press in the context of an increasingly busy NHS.

Herbert Freudenberger, an American psychologist, was the first to publish a paper in a psychology journal on long-term unresolvable job stress using the word 'burnout' and is the name most associated with the condition. ${ }^{1}$ It is not considered a mental illness; the International classification of diseases: ICD-11 for mortality and morbidity statistics (ICD-11) describes burnout as

Authors: ${ }^{\text {A }}$ consultant paediatrician, Taunton and Somerset NHS Trust, Taunton, UK; ${ }^{B}$ consultant vascular surgeon, Taunton and Somerset NHS Trust, Taunton, UK; ${ }^{C}$ consultant cardiologist, Taunton and Somerset NHS Trust, Taunton, UK and honorary senior lecturer, Exeter University, UK a consequence of workplace stress characterised by exhaustion, mental distance from the job and reduced efficacy. ${ }^{2}$ The decision to include burnout in ICD-11 was warmly welcomed by the World Medical Association. ${ }^{3}$

Burnout is important for both physicians and patients. Burnout can adversely affect a physician's professionalism and 'sense of calling', ${ }^{4,5}$ It has been linked to alcohol misuse, the breakdown of personal relationships, depression and suicide. ${ }^{6-8}$ It can have an adverse effect on patient safety, such as an increased rate of major surgical complications and death. ${ }^{9-12}$ Panagioti et al also noted that burnout was associated with reduced patient satisfaction. $^{12}$

It is unclear whether particular specialties, genders or age groups of doctors are more at risk of burnout than others, due to inconsistencies in the burnout literature. ${ }^{13}$ Among doctors in training, the specialties identified as most at risk are radiology and general surgery. ${ }^{14}$

Because of the consequence of burnout to patients and doctors, we aimed to audit the level of burnout within our district general hospital (DGH) across all senior doctors. We were concerned that the increasing winter pressures and staff vacancies were having an adverse impact on our workforce and we sought to establish a baseline as part of a programme of work to improve physician wellbeing.

We hypothesised that we would find differences in rates of burnout between different specialities, genders, time in the job, and between consultants and staff grade, associate specialist and specialty (SAS) doctors.

\section{Methods}

A survey was created on an online survey collection tool (SurveyMonkey). Demographic data was collected including gender, grade (SAS or consultant), number of years in post $(0-4,5-9,10-14,15+)$ and in which of the five clinical directorates the respondent worked (medicine; surgery and anaesthetics; haematology, oncology and palliative care; women and children; and clinical support). Only nonidentifiable data was collected and the survey was distributed with a statement of anonymity preceding any questioning.

The survey was open between 04 January 2018 and 21 January 2018. The link was sent to the entire cohort of consultant and SAS doctors employed at Taunton and Somerset NHS Foundation Trust (TSFT; 236 consultants and 55 SAS doctors) by email. Separate emails were sent to groups of consultants and SAS doctors by directorate to encourage participation. 
For the purpose of this study, the abbreviated Maslach Burnout Inventory (aMBI) was selected; the survey was licenced from Mind Garden, Menlo Park, USA. The aMBI is a reliable and highly validated tool that has been used to measure burnout in doctors and other healthcare professionals. ${ }^{15-21}$

To assess burnout, there were nine questions from the aMBI, and three additional questions concerning satisfaction with medicine. ${ }^{19}$ Questions were scored on a seven-point scale, ranging from never ( 0 ) to every day (6). As per the instructions for the full Maslach Burnout Inventory, each domain was scored separately.

We assumed that an emotional exhaustion score of $(E E) \geq 9$, a depersonalisation score (DP) $\geq 6$ or a personal accomplishment score $(P A) \leq 10$ represented a high risk of burnout. ${ }^{16,22,23}$ Further details on the aMBI (assumptions for calculation of high risk of burnout) can be found in supplementary material S1 and online (www.mindgarden.com/117-maslach-burnout-inventory).

We calculated the total numbers of doctors who scored over the threshold to be considered at high risk of burnout for each scale of the aMBI, and the average score on the satisfaction with medicine scale, and compared genders, consultants and SAS doctors, time in post ( $0-9$ years vs 10 years or more), and the clinical directorate of medicine vs the clinical directorate of surgeons and anaesthetists. We compared the latter two groups as there were sufficient numbers within these directorates to enable a statistical comparison.

Prism 7 (GraphPad, San Diego, USA) was used for data analysis. Categorical data was analysed using Fisher's exact test. Continuous variables were analysed using t-tests.

As an audit, ethical approval was not required.

\section{Results}

\section{Demographics}

One-hundred and seventy-eight participants started the survey but three entered no data, therefore 175 (60\% of the total consultant and SAS cohort) completed the survey. Only the data from those who completed the survey were included in the analysis. Responses were distributed over the clinical directorate areas with 53 (30\%) of respondents from medicine; 69 (39\%) from surgery and anaesthetics; 13 (7\%) from haematology, oncology and palliative care; 20 (11\%) from women and children; and 15 (8\%) from clinical support; five responses did not specify clinical directorate; 100 were male and 75 were female; 148 $(85 \%)$ were consultants and 27 were SAS doctors; and $38(22 \%)$ were in post for $0-4$ years, $47(27 \%)$ for $5-9$ years, $40(23 \%)$ for $10-14$ years and $50(29 \%)$ for 15 years or more. The responses reflected well the general make-up of the workforce, although the SAS response rate was slightly lower than the consultant response rate.

\section{Responses: burnout results using aMBI}

\section{Emotional exhaustion}

Sixty-five (38.7\%) participants scored 9 or greater, indicating a high risk of burnout; 10 did not complete the questions to allow scoring (Fig 1).

\section{Depersonalisation}

Thirty-one (18.7\%) participants scored 6 or greater, indicating a high risk of burnout; 12 did not complete the questions to allow scoring (Fig 2).

\section{Personal accomplishment}

Thirty-six $(21.7 \%)$ participants scored $\leq 10$ on the PA domain, indicating a high risk of burnout; $12(7 \%)$ did not complete the questions to allow scoring (Fig 3).

\section{High risk of burnout}

Eighty-eight (49.4\%) participants scored one or more of EE $\geq 9$, DP $\geq 6$ or $P A \leq 10$, representing a high risk of burnout.

\section{Comparisons between groups}

There were no significant differences between genders, grades, length of service or clinical directorates. There was a trend towards men being more depersonalised than women ( $21.7 \%$ vs $14.9 \%$; $p=0.32$ ). Fewer SAS doctors were at high risk of burnout compared with consultant staff, but again, the scores were not significantly different ( $9 / 26$ (34.6\%) vs 79/144 (54.9\%); $p=0.0867)$. Full details can be found in supplementary material S1.
Fig 1. Emotional exhaustion. A chart of the scores on the emotional exhaustion scale. A score of $\geq 9$ indicates high emotional exhaustion.

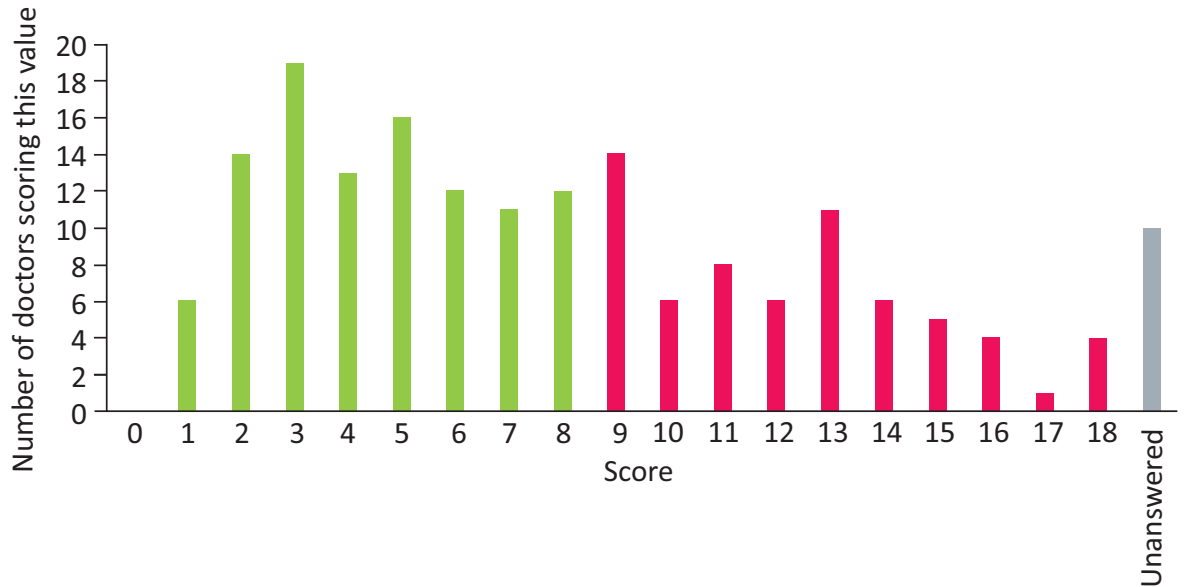




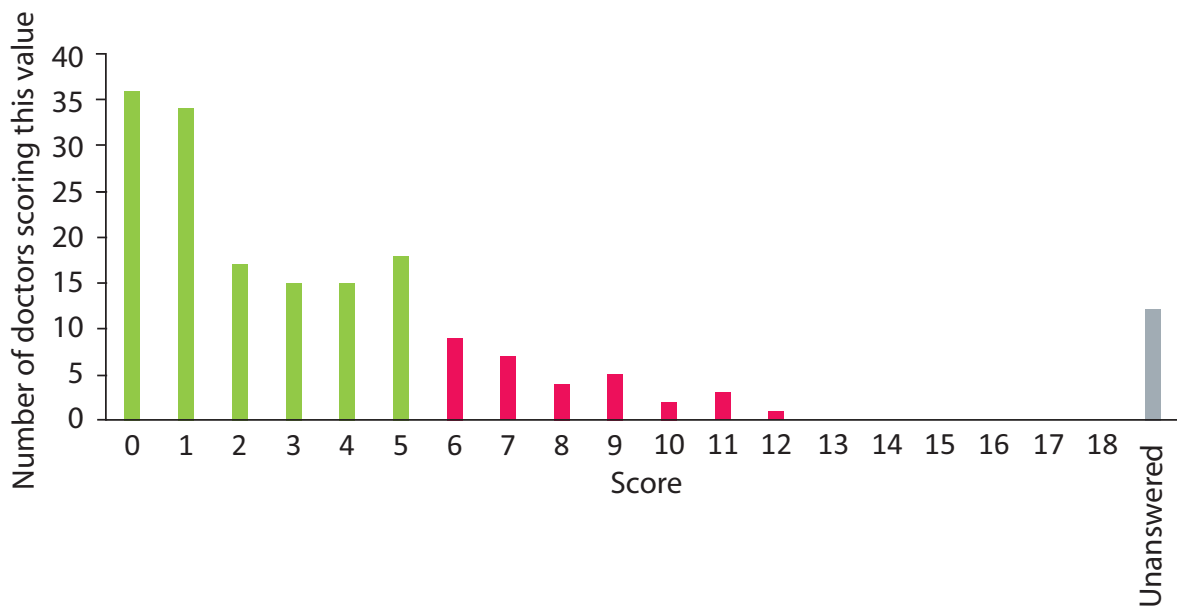

Fig 2. Depersonalisation. A chart of the scores on the depersonalisation scale. A score of $\geq 6$ indicates high depersonalisation.

\section{Discussion}

We aimed to estimate the risk of burnout among senior clinicians within our hospital, because of the potential risks to patients and staff. We surveyed 236 consultants and 55 SAS doctors at our trust, using the aMBI; $175(60 \%)$ completed the survey; $49 \%$ of consultants and SAS doctors who responded to the survey were estimated to be at high risk of burnout. There were no significant differences between genders, grades, length of service or clinical directorates.

This appears to be the largest study in senior clinicians in one institution in the UK and it comes at a time of unique pressures within the NHS. The evidence base for burnout within UK senior medical staff data is sparse, but selected studies utilising the Maslach Burnout Inventory, the most established tool for assessing burnout, in UK based clinicians have shown a rate of between $28-32 \%$ of risk of burnout on at least one of the MBI subscales. ${ }^{24}$ This suggests that the doctors in our survey were possibly more significantly affected compared with others in the UK, but data from the USA show that $50 \%$ of physicians are affected by burnout, a figure more consistent with our findings. ${ }^{24}$
The survey was conducted at a busy time of year, which may have affected the results. TSFT is a middle-sized DGH in the south west of the UK with approximately 600 beds. In the 5 -week period prior to the survey, there was an $16 \%$ increase rate of ambulance conveyances compared to same time the previous year. This was against a background of a nationally recognised picture of a trend to increasing hospital admissions. Historical comparison data also revealed an unfilled consultant post gap of $7 \%$ in 2017 compared to $2.5 \%$ in 2016 . Our survey opened on 04 January 2018; 04 January 2018 was, in retrospect, shown to be the busiest day at our hospital over a 12-month period.

Equally, there are factors which might have been expected to reduce the risk of burnout. TSFT is a progressive supportive trust; the trust was ranked the third highest rated trust in the 2017-18 Listening into Action NHS national staff survey when staff were asked to rate their trust leadership and culture. The trust has also scored within the top $20 \%$ for staff engagement, and also as a trust recommended by staff as a place to work or receive treatment. ${ }^{25,26}$ It is important to remember that there is no definitive score that 'proves' a person is burned out. ${ }^{10}$ Although the MBI is a well validated tool among healthcare professionals, its conclusions

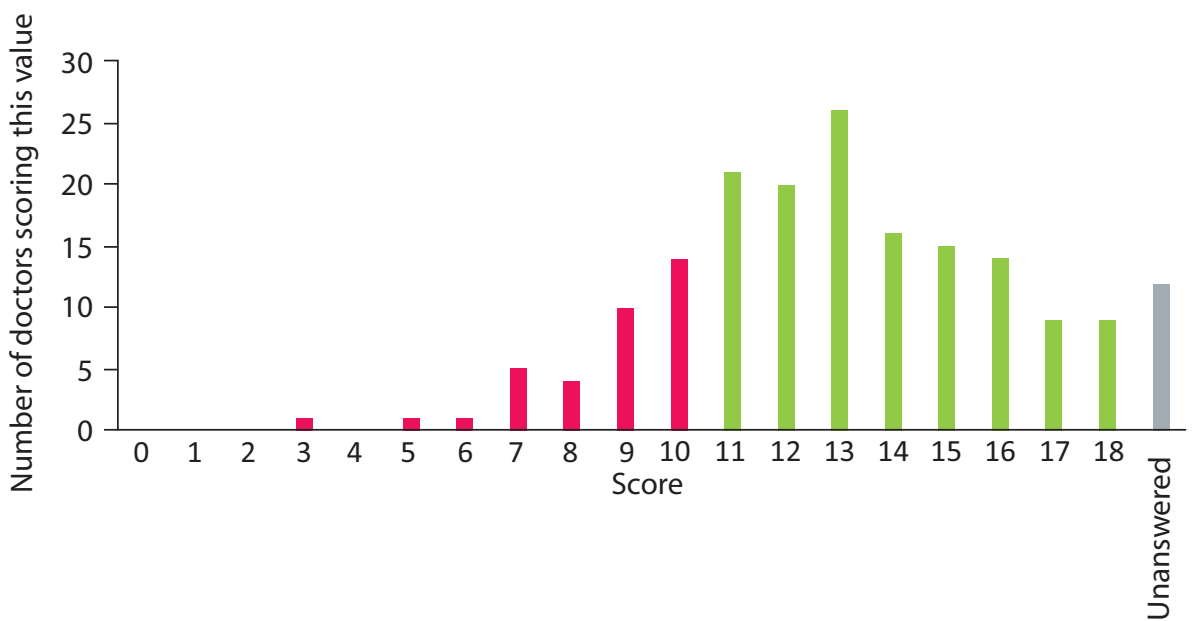

Fig 3. Personal accomplishment. A chart of the scores on the personal accomplishment scale. A score of $<11$ indicates low personal accomplishment. 
should be taken as an indication of the potential number of individuals who may be at higher risk of burnout. ${ }^{11-15,23}$

It should also be noted, that although a $60 \%$ response rate is high for a survey, $40 \%$ of the doctors did not complete the survey, and therefore it is possible that the true rates of burnout are lower (or higher) than we have found.

Given that this study was only conducted in one DGH in the UK $\mathrm{NHS}$, there are clear limitations with regards to the generalisability of results. These results may not be generalisable to other hospitals in the UK, although it is likely that other DHGs in the UK face similar pressures, or beyond the UK, but it adds to the evidence base that burnout is a widespread problem.

Despite the limitations of our study, it is clear from this study, and others, that burnout is likely to be a widespread issue among medical staff throughout the NHS. We would argue that such surveys should be undertaken in other institutions to verify or refute our results. Because of the impact of burnout on physician and patient health, it is clear that strategies need to be adopted by hospitals where burnout is identified to improve outcomes. There is emerging literature concerning the importance of organisations addressing wellbeing (and subsequent reduction in burnout) to inform wellbeing strategies. Prioritising both formal and informal support for clinicians, as well as accepting there needs to be a range of support available, is paramount. ${ }^{27}$ Support can include availability of 1:1 advice, counselling alongside mentoring and coaching from identified colleagues, group reflection such as Schwartz rounds, and other resources for wellbeing and support. Recently, a pilot study of coaching showed significant benefits in reducing emotional exhaustion, for example. ${ }^{28}$ Small changes, such as reduced interruptions and conflicting demands, as well as improved coordination and support among teams may be beneficial for not only improved working conditions for team members but also enhancing quality of care. ${ }^{29}$

Delivery of a wellbeing strategy requires resourcing. Shanafelt et al examined nine organisational strategies to promote engagement and staff burnout as well as clarified the business case pertinent to justifying investment with respect to investing in physician well-being. ${ }^{30,31}$ Shanafelt and Noseworthy comment that 'deliberate, sustained, and comprehensive efforts by the organization to reduce burnout and promote engagement can make a difference,' and that 'Leadership and sustained attention from the highest level of the organization are the keys to making progress. ${ }^{30}$ Looking at 'The business case for investing in physician well-being,' Shanafelt and colleagues look at the advantages to investment in the process both in terms of the organisation's ethical responsibility to its staff and patients but also stating it is the 'fiscally responsible one.."

\section{Conclusions}

The risk of senior clinician burnout at our hospital is high. This appears to be independent of grade, gender or clinical directorate. At the busiest time of the year, up to $49 \%$ of senior clinicians were graded as being at a high risk of burnout using the aMBI, potentially adversely affecting patient care. Investing in physician wellbeing is an evidence-based and cost-effective strategy and should be used to help address this problem in an NHS which will only get busier. As a consequence of this work and other observations, our trust has appointed a lead for physician wellbeing and a programme of work is being devised to address the level of burnout identified. We would advocate that other organisations examine the level of burnout among their medical staff and take action if required.

\section{Supplementary Material}

Additional supplementary material may be found in the online version of this article at www.rcpjournals.org/content/clinmedicine: S1 - Further details on the abbreviated Maslach Burnout Inventory information and comparison data tables.

\section{Conflicts of Interest}

Dr Mark Dayer has accepted support to attend conferences from Biotronik and Daiichi Sankyo, and speaker fees from Biotronik.

\section{Acknowledgments}

We would like to thank all our colleagues for completing the survey. We are also grateful for the informal feedback from colleagues from multiple corridor discussions.

\section{References}

1 Freudenberger HJ. Staff burn-out. Journal of Social Issues 1974:30:159-65.

2 World Health Organization. International classification of diseases: ICD-11 for mortality and morbidity statistics (ICD-11 MMS). WHO, 2019:QD85.

3 World Medical Association. World Medical Association welcomes decision on burnout. WMA, 2019. www.wma.net/news-post/worldmedical-association-welcomes-decision-on-burnout

4 Dyrbye LN, Massie FS Jr, Eacker A et al. Relationship between burnout and professional conduct and attitudes among US medical students. JAMA 2010;304:1173-80.

5 Jager AJ, Tutty MA, Kao AC. Association between physician burnout and identification with medicine as a calling. Mayo Clin Proc 2017;92:415-22.

6 Ahola K, Vaananen A, Koskinen A et al Burnout as a predictor of all-cause mortality among industrial employees: a 10-year prospective register-linkage study. J Psychosom Res 2010;69:51-7.

7 Oreskovich M, Anderson J. Physician personalities and burnout. Bull Am Coll Surg 2013;98:40-2.

8 Shanafelt TD, Balch CM, Dyrbye L et al. Special report: suicidal ideation among American surgeons. Arch Surg 2011;146:54-62.

9 Mazzocco K, Petitti DB, Fong KT et al. Surgical team behaviors and patient outcomes. Am J Surg 2009;197:678-85.

10 Dewa CS, Loong D, Bonato $S$ et al. How does burnout affect physician productivity? A systematic literature review. BMC Health Serv Res 2014;14:325.

11 Dewa CS, Loong D, Bonato $S$ et al. The relationship between resident burnout and safety-related and acceptability-related quality of healthcare: a systematic literature review. BMC Med Educ 2017;17:195.

12 Panagioti M, Geraghty K, Johnson ] et al. Association between physician burnout and patient safety, professionalism, and patient satisfaction: a systematic review and meta-analysis. JAMA Intern Med 2018;178:1317-30.

13 Rotenstein LS, Torre M, Ramos MA et al. Prevalence of burnout among physicians: a systematic review. JAMA 2018;320:1131-50.

14 Low ZX, Yeo KA, Sharma VK et al. Prevalence of burnout in medical and surgical residents: a meta-analysis. Int J Environ Res Public Health 2019;16:E1479.

15 Bawakid K, Abdulrashid O, Mandoura N et al. Burnout of physicians working in primary health care centers under Ministry of Health Jeddah, Saudi Arabia. Cureus 2017;9:e1877.

16 Langade D, Modi PD, Sidhwa YF et al. Burnout syndrome among medical practitioners across India: A questionnaire-based survey. Cureus 2016:8:e771. 
17 Lebares CC, Guvva EV, Ascher NL et al. Burnout and stress among US surgery residents: Psychological distress and resilience. J Am Coll Surg 2018;226:80-90.

18 McManus IC, Gordon D, Winder BC. Duties of a doctor: UK doctors and good medical practice. Qual Health Care 2000;9:14-22.

19 McManus IC, Smithers E, Partridge P et al. A levels and intelligence as predictors of medical careers in UK doctors: 20 year prospective study. BMJ 2003;327:139-42.

20 McManus IC, Winder BC, Gordon D. UK doctors' attitudes to the General Medical Council's performance procedures, 1997-99. Med Educ 2001;35(Suppl 1):60-9.

21 McManus IC, Winder BC, Gordon D. The causal links between stress and burnout in a longitudinal study of UK doctors. Lancet 2002;359:2089-90.

22 Maslach C, Jackson SE. Maslach burnout inventory. Palo Alto: Consulting Psychologists Press, 1986.

23 Elmore $L C$, Jeffe $D B$, Jin $L$ et al. National survey of burnout among US general surgery residents. J Am Coll Surg 2016;223:440-51.

24 Shanafelt TD, Dyrbye LN, West CP. Addressing physician burnout: the way forward. JAMA 2017;317:901-2.

25 NHS Survey Coordination Centre. Staff survey 2017. NHS, 2017.

26 Listening into Action. NHS national staff survey. LiA, 2018.
27 Tayfur O, Arslan M. The role of lack of reciprocity, supervisory support, workload and work-family conflict on exhaustion: evidence from physicians. Psychol Health Med 2013;18:564-75.

28 Dyrbye LN, Shanafelt TD, Gill PR et al. Effect of a professional coaching intervention on the well-being and distress of physicians: a pilot randomized clinical trial. JAMA Intern Med 2019 [Epub ahead of print].

29 Weigl M, Hornung S, Angerer P et al. The effects of improving hos pital physicians working conditions on patient care: a prospective, controlled intervention study. BMC Health Serv Res 2013;13:401.

30 Shanafelt TD, Noseworthy JH. Executive leadership and physician well-being: nine organizational strategies to promote engagement and reduce burnout. Mayo Clin Proc 2017;92:129-46.

31 Shanafelt T, Goh J, Sinsky C. The business case for investing in physician well-being. JAMA Intern Med 2017;177:1826-32.

Address for correspondence: Dr Mark Dayer, Taunton and Somerset NHS Trust, Musgrove Park, Taunton, Somerset TA1 5DA, UK.

Email: markdayer@gmail.com 